\title{
Numerical Calculation of Effect of Elastic Deformation on Aerodynamic Characteristics of a Rocket
}

\author{
Laith K. Abbas, Dongyang Chen, and Xiaoting Rui \\ Institute of Launch Dynamics, Nanjing University of Science and Technology, Nanjing 210094, China \\ Correspondence should be addressed to Laith K. Abbas; laithabbass@yahoo.com
}

Received 1 September 2013; Revised 28 December 2013; Accepted 2 January 2014; Published 17 February 2014

Academic Editor: Linda L. Vahala

Copyright (C) 2014 Laith K. Abbas et al. This is an open access article distributed under the Creative Commons Attribution License, which permits unrestricted use, distribution, and reproduction in any medium, provided the original work is properly cited.

\begin{abstract}
The application and workflow of Computational Fluid Dynamics (CFD)/Computational Structure Dynamics (CSD) on solving the static aeroelastic problem of a slender rocket are introduced. To predict static aeroelastic behavior accurately, two-way coupling and inertia relief methods are used to calculate the static deformations and aerodynamic characteristics of the deformed rocket. The aerodynamic coefficients of rigid rocket are computed firstly and compared with the experimental data, which verified the accuracy of CFD output. The results of the analysis for elastic rocket in the nonspinning and spinning states are compared with the rigid ones. The results highlight that the rocket deformation aspects are decided by the normal force distribution along the rocket length. Rocket deformation becomes larger with increasing the flight angle of attack. Drag and lift force coefficients decrease and pitching moment coefficients increase due to rocket deformations, center of pressure location forwards, and stability of the rockets decreases. Accordingly, the flight trajectory may be affected by the change of these aerodynamic coefficients and stability.
\end{abstract}

\section{Introduction}

Aeroelastic is a discipline which is used to study aerodynamics and elastic structure interaction and its application. A slender rocket is usually to be faced with serious aeroelastic problems when light weight and low stiffness structures are used. Aeroelastic problems should be considered in the early phase of the slender rocket structural design since any unstable response to aerodynamic loading may quickly lead to catastrophic structural failure, which may need usually expensive modifications. Flight tests and wind tunnels are two expensive ways performed in the late phase of the design. Therefore, computational aeroelasticity dynamics methods are used in order to calculate aeroelastic characteristics of the rocket during its development stages. With Computational Fluid Dynamics (CFD) technology and the increasing advance of computing power, computer aided engineering (CAE) analysis which integrated CFD analysis accurately computes the aerodynamic coefficients of many complex geometry [1] and complex flow phenomena [2, 3] and Computational Structure Dynamics (CSD) which solves the structural static and dynamic problems $[4,5]$ is a useful method to solve aeroelastic problems of flight vehicles accurately [6-8].

In this paper, in order to solve the static aeroelastic problem of a slender wrap fins rocket in the linear angleof-attack range, a two-way coupling approach is developed. To conduct this static aeroelastic analysis, ANSYS Workbench multiphysics coupling platform, which includes fluid, structural solvers, and coupling module, namely, FLUENT, ANSYS Mechanical, and System coupling, is used to solve the displacements associated with the aerodynamic pressure loading and find out the static aeroelastic behavior of this rocket in the nonspinning and spinning state. The single reference frame (SRF) model is used to perform the problem of spinning rocket [9]. CFD grid is deformed to be able to obtain aerodynamic solutions of the deformed geometry using dynamic mesh which is called diffusion-based smoothing method. For the structural analysis, the ANSYS Mechanical inertia relief option $[10,11]$, which is based on d'Alembert principle and used to simulate unconstrained rockets in flight and make sure the rocket has no rigid body displacement, is used with the linear elastic solver. The aerodynamic coefficients distribution of the spinning 
TABLE 1: Rocket segmentation.

\begin{tabular}{rcccccccccc}
\hline & Part 1 $\left(x_{1} / D\right)$ & 1 & 2 & 2.3 & & Part 2 $\left(x_{2} / D\right)$ & 0.2 & 0.4 & 0.6 & 0.8 \\
\hline 1.5 & 2 & 3 & 4 & 5 & 6 & 7 & 8 & 9 & 10 & 11 \\
13 & 14 & 15 & 16 & 17 & 18 & 19 & 20 & 21 & Part 3(x $/ D)$ & 2 \\
\hline
\end{tabular}

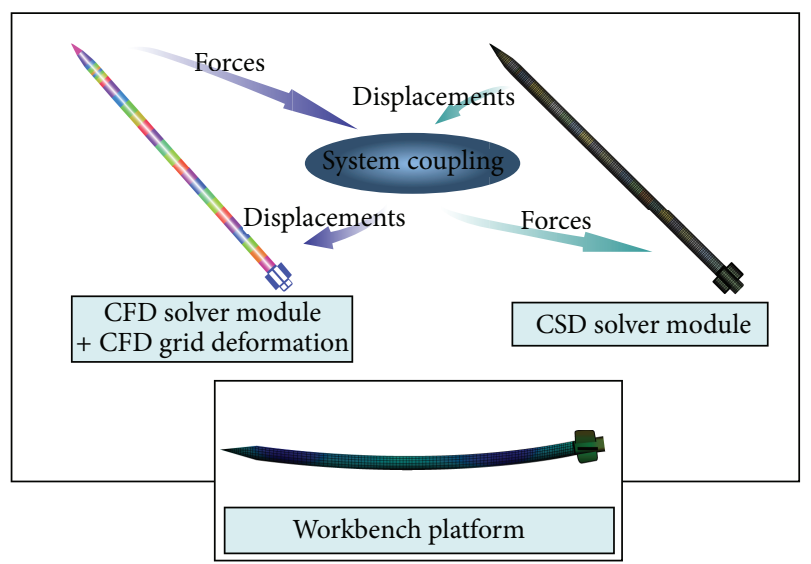

FIgURE 1: Scheme of CAE code ANSYS Workbench.

TABLE 2: Material properties for rocket.

\begin{tabular}{lccc}
\hline Part name & Density & Young's modulus & Poisson's ratio \\
\hline Part 1, Part 3 & 7850 & $2 E+11$ & 0.3 \\
Part 2 & 2770 & $7.1 E+10$ & 0.33 \\
\hline
\end{tabular}

rigid rocket and the elastic one are calculated and compared with that of nonspinning ones. The steps of static aeroelastic calculations are described and the coupling procedure is explained in the following section.

\section{Static Aeroelastic Calculations}

2.1. Problem Definition. In the reality, the rigid geometry assumption holds for many engineering problems. In many cases, where the structures are flexible, fluid-structure interactions become important. In this work, a slender wrap fins rocket is studied. Static aeroelasticity considers the nonoscillatory effects of aerodynamic forces acting on the elastic structure [12]. Because of the elastic nature of the slender rocket, aerodynamic forces acting on the rocket contribute to structural deformation. This deflection of the structure tends to redistribute the aerodynamic forces acting on the rocket, and this interaction continues by leading to each other. For accurately simulating the static aeroelastic of free flight rocket, spinning is considered and structured mesh is adopted. As a result, a coupling approach is developed to solve the static aeroelastic problem as a significant part of rocket design workflow.

2.2. Solution Procedure. Two-way fluid structure method flow chart is shown in Figure 1.
The static aeroelastic solutions of the nonspinning and spinning rockets are obtained using the following steps.

(1) Generate rocket geometry and fluid control volume by SPACECLAIM.

(2) Generate a structured mesh by ICEM-CFD around the rigid rocket geometry.

(3) Obtain a steady-state CFD solution for the rigid rocket by FLUENT.

(4) Export the pressures on the rocket surface in ANSYS Mechanical by System coupling module.

(5) Map the pressure at the CFD grid points to forces on the CSD nodes.

(6) Obtain the structural response of the rocket by CSD code of ANSYS Mechanical.

(7) Map the displacement at the CSD nodes to the displacements on the CFD grid points of the rocket surface by System coupling module.

(8) Deform the whole CFD mesh.

(9) Obtain steady-state CFD solution for the deformed rocket by FLUENT.

(10) Repeat steps 4-9 until the displacement and aerodynamic coefficients do not change.

\subsection{Numerical Method}

2.3.1. Geometry Model and Initial Conditions. The model used in this work is a wrap fins rocket with a slenderness ratio of more than 25 . For comparing with the aerodynamic loads distribution of the elastic slender rocket, it is divided into many segments along the rocket body. Then, through computation, the aerodynamic parameters of every segment are obtained. The slender rocket consists of three parts as shown in Figure 2(a). Longitudinally, the body is divided into 31 segments as tabulated in Table 1 . The middle point of each section is the normal force action point. The geometry model of the rocket and the flow control volume (see Figure 2(b)) are established. The far-field should be placed far enough from the rocket since the free stream of infinity is defined as boundary conditions. For supersonic computation, the rocket has the far-field boundary located at about $5 D$ (where $D$ is the rocket diameter) upstream away from the rocket-nose, about $30 D$ away from the rocket-bottom downstream, and about $15 D$ away from the rocket-surface in a lateral (see Figure 2(b)).

The aerodynamic parameters distribution of the rigid rocket are calculated in the conditions that the angle of attacks is $2^{\circ}$ and $4^{\circ}$, while the Mach numbers are 1.5, 2, 2.5, and 3 , respectively. The rocket three parts maintain the defined 


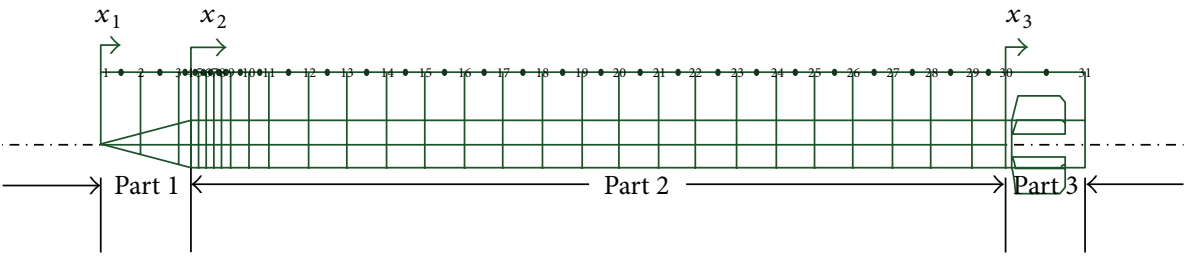

(a)

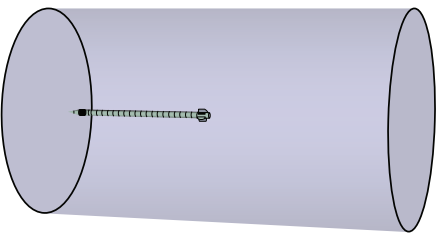

(b)

FIGURE 2: Model geometry and flow control volume: (a) longitudinal division of the slender rocket and (b) flow control volume.

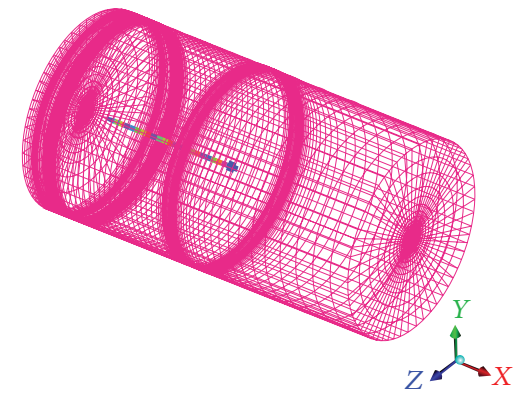

(a)

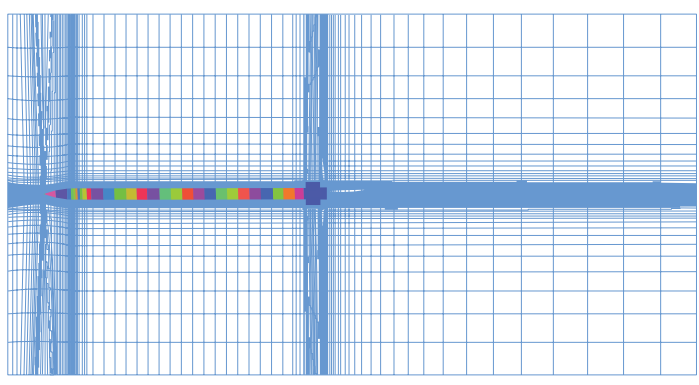

(b)

FIGURE 3: Discrete mesh: (a) flow field grids and (b) the section of grids.

density, Poisson's ratio, and Young's modulus, respectively (see Table 2).

2.3.2. CFD Governing Equations. For CFD problems, Direct Numerical Simulation (DNS) solves the Navier-Stokes (NS) equations directly without the turbulent model needing high speed and large memory computer due to their high nonlinearity and complexity. It is impossible to adopt this method in practical engineering. Decomposing the N-S equations into the RANS equations makes it possible to simulate engineering fluid dynamic problems.

Reynolds averaged N-S equations (RANS) can be expressed as

$$
\frac{\partial \mathbf{Q}}{\partial t}+\frac{\partial \mathbf{E}}{\partial x}+\frac{\partial \mathbf{F}}{\partial y}+\frac{\partial \mathbf{G}}{\partial z}=\frac{\partial \mathbf{E}_{v}}{\partial x}+\frac{\partial \mathbf{F}_{v}}{\partial y}+\frac{\partial \mathbf{G}_{v}}{\partial z}
$$

where

$$
\begin{gathered}
\mathbf{Q}=[\rho, \rho u, \rho v, \rho w, \rho E]^{T} \\
\mathbf{E}=\left[\rho u, \rho u^{2}+p, \rho u v, \rho u w,(\rho E+p) u\right]^{T}, \\
\mathbf{F}=\left[\rho v, \rho v u, \rho v^{2}+p, \rho v w,(\rho E+p) v\right]^{T}, \\
\mathbf{G}=\left[\rho w, \rho w u, \rho w v, \rho w^{2}+p,(\rho E+p) w\right]^{T}, \\
\mathbf{E}_{v}=\left[0, \tau_{x x}, \tau_{x y}, \tau_{x z}, \beta_{x}\right]^{T}, \\
\mathbf{F}_{v}=\left[0, \tau_{y x}, \tau_{y y}, \tau_{y z}, \beta_{y}\right]^{T}, \\
\mathbf{G}_{v}=\left[0, \tau_{z x}, \tau_{z y}, \tau_{z z}, \beta_{z}\right]^{T},
\end{gathered}
$$

where $\rho$ is the fluid density, $(u, v, w)$ are the three components of the Cartesian coordinate system, $p$ is pressure, and $E$ is total energy of unit mass.
N-S equations of rotating coordinates [9] are

$$
\begin{gathered}
\frac{\partial \rho}{\partial t}+\frac{\partial}{\partial x_{j}}\left(\rho w_{j}\right)=0 \\
\frac{\partial}{\partial t}\left(\rho u_{i}\right)+\frac{\partial}{\partial x_{j}}\left(\rho w_{j} w_{i}+p \delta_{i j}\right)=\frac{\partial}{\partial x_{j}}\left(\tau_{i j}\right)+\rho F_{i}, \\
\frac{\partial}{\partial t}\left(\rho E^{\prime}\right)+\frac{\partial}{\partial x_{j}}\left(\rho w_{j} E^{\prime}+w_{j} p\right) \\
=\frac{\partial}{\partial x_{j}}\left(w_{i} \tau_{i j}+k \frac{\partial T}{\partial x_{j}}\right)+\rho \bar{q}+\rho f_{i} w_{i}
\end{gathered}
$$

where

$$
\begin{gathered}
\tau_{i j}=\mu\left[\left(\frac{\partial w_{i}}{\partial x_{j}}+\frac{\partial w_{j}}{\partial x_{i}}\right)-\frac{2}{3} \delta_{i j} \frac{\partial w_{k}}{\partial x_{k}}\right], \\
F_{i}=f_{i}-2 e_{i j k} \omega_{j} w_{k}+\frac{\partial}{\partial x_{j}}\left(\frac{\omega^{2} R^{2}}{2}\right), \\
E^{\prime}=e+\frac{W^{2}}{2}-\frac{\omega^{2} R^{2}}{2}=\frac{P}{\rho(\gamma-1)}+\frac{W^{2}}{2}-\frac{\omega^{2} R^{2}}{2},
\end{gathered}
$$

where $W$ is the relative speed, $E^{\prime}$ is the total energy of relative rotation, and $\bar{q}$ is the radiant heat $(\bar{q}=0$ in the present study). $F$ is the external force, including volume force and centrifugal force. $\omega$ is the angular velocity of rotation and $R$ is the radius of gyration.

For the closure of the above equations, the shear stress transport (SST) $k$ - $\omega$ turbulence model developed by Menter $[13,14]$ is used. SST model integrated the advantages of standard $k-\varepsilon$ and standard $k-\omega$ model boundary layer inside and outside. $k$ and $\omega$ transport equation can be written as [14] 
FIGURE 4: Solid region grid.

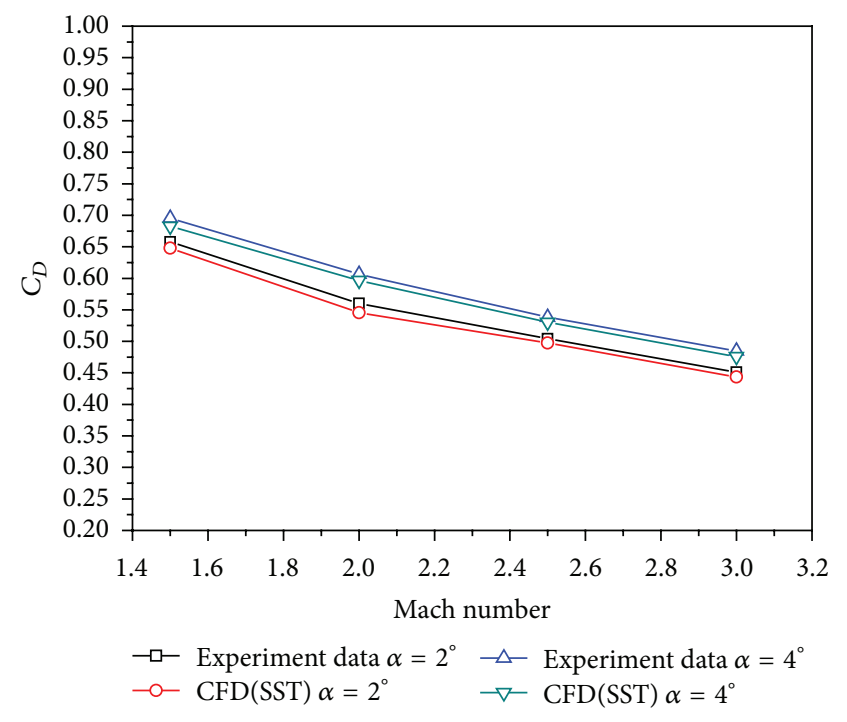

(a)

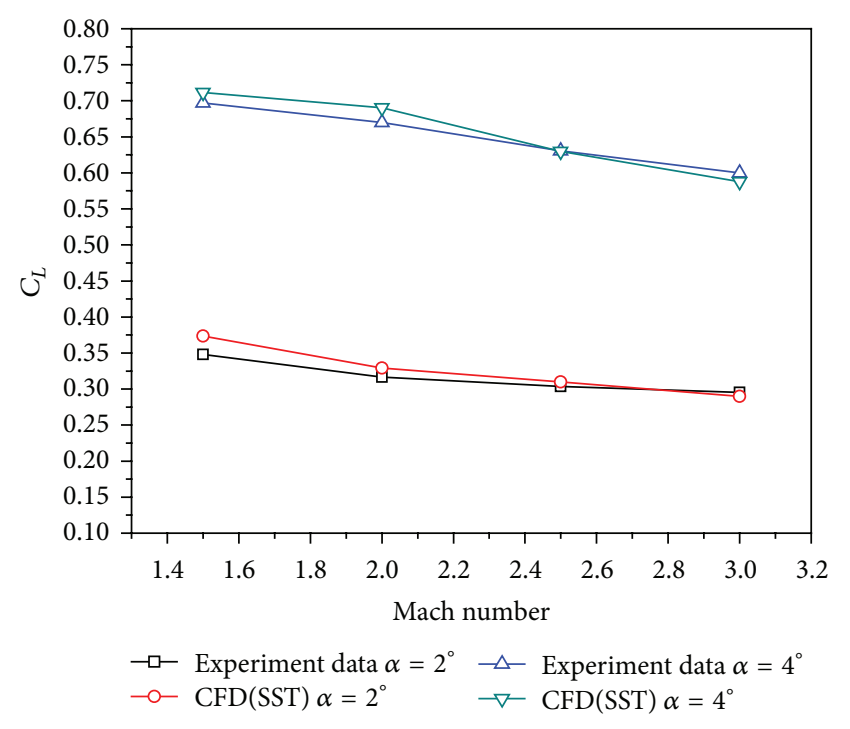

(b)

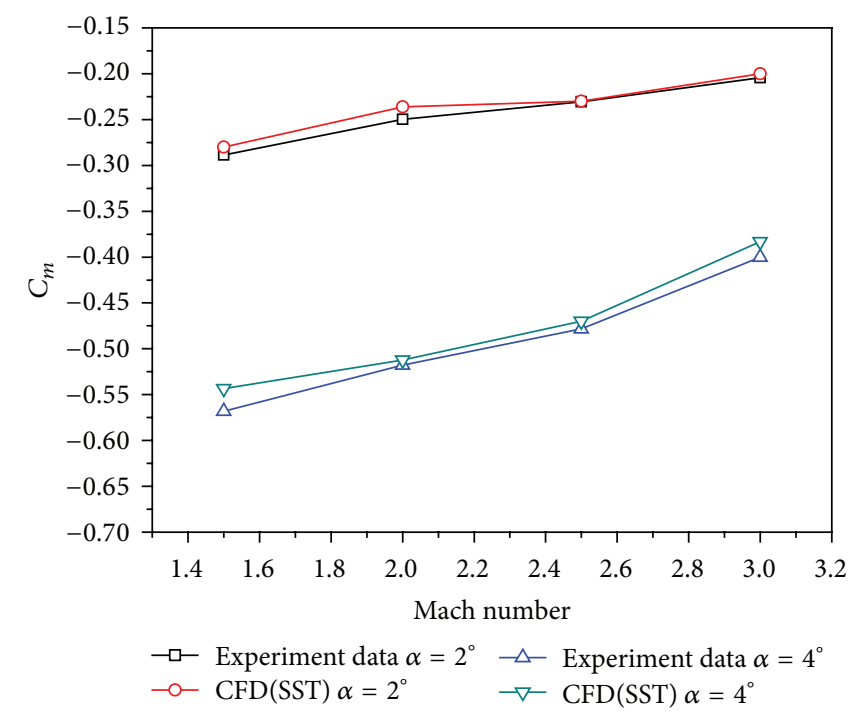

(c)

Figure 5: Aerodynamics coefficients versus Mach number (Ma): (a) $C_{D}$, (b) $C_{L}$, and (c) $C_{m}$.

$$
\begin{aligned}
\frac{d(\rho k)}{d t}= & \tau_{i j} \frac{\partial u_{i}}{\partial x_{j}}-\beta^{*} \rho \omega k+\frac{\partial}{\partial x_{j}}\left[\left(\mu+\sigma_{k} \mu_{t}\right) \frac{\partial k}{\partial x_{j}}\right], \\
\frac{d(\rho \omega)}{d t}= & \frac{\gamma \rho}{\mu_{t}} \tau_{i j} \frac{\partial u_{i}}{\partial x_{j}}-\beta \rho \omega^{2}+\frac{\partial}{\partial x_{j}}\left[\left(\mu+\sigma_{\omega} \mu_{t}\right) \frac{\partial \omega}{\partial x_{j}}\right] \\
& +2 \rho\left(1-F_{1}\right) \sigma_{\omega 2} \frac{1}{\omega} \frac{\partial k}{\partial x_{j}} \frac{\partial \omega}{\partial x_{j}},
\end{aligned}
$$

where $\tau_{i j}$ is the shear stress:

$$
\tau_{i j}=\mu_{t}\left(\frac{\partial u_{i}}{\partial x_{j}}+\frac{\partial u_{j}}{\partial x_{i}}-\frac{2}{3} \frac{\partial u_{k}}{\partial x_{k}} \delta_{i j}\right)-\frac{2}{3} \rho k \delta_{i j} .
$$

Blending function $F_{1}$ is

$$
F_{1}=\tanh \left(\arg _{1}^{4}\right),
$$




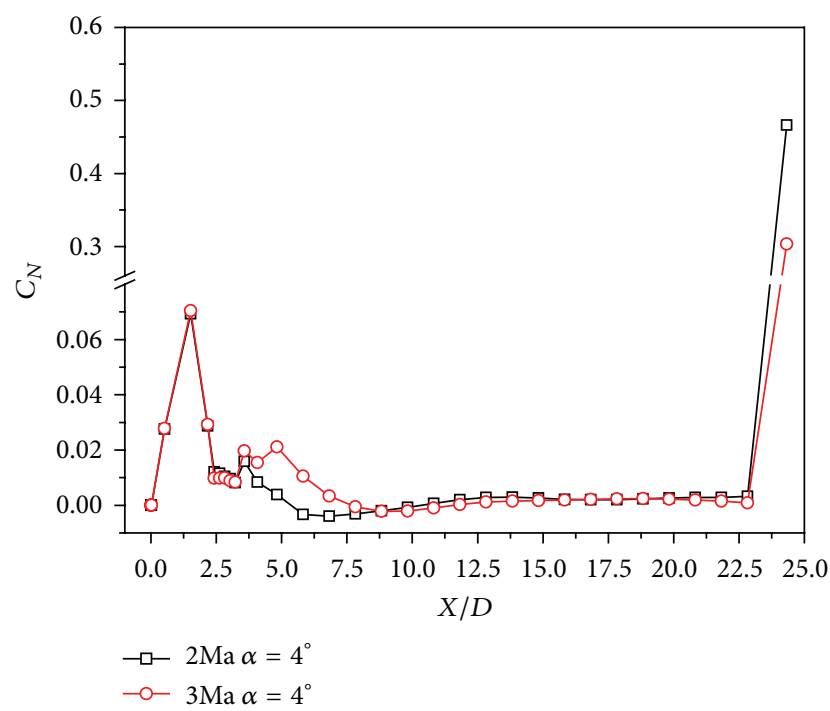

FIGURE 6: Distributed normal force coefficients along rocket length.

where

$$
\begin{gathered}
\arg _{1}=\min \left[\max \left(\frac{\sqrt{k}}{0.09 \omega y}, \frac{500 v}{y^{2} \omega}\right), \frac{4 \rho \sigma_{\omega 2} k}{C D_{k \omega} y^{2}}\right], \\
C D_{k \omega}=\max \left(2 \rho \sigma_{\omega 2} \frac{1}{\omega} \frac{\partial k}{\partial x_{j}} \frac{\partial \omega}{\partial x_{j}}, 10^{-20}\right) .
\end{gathered}
$$

The eddy viscosity is defined as

$$
\mu_{t}=\frac{\rho \alpha_{1} k}{\max \left(\alpha_{1} \omega, \Omega F_{2}\right)},
$$

where $\Omega$ is the absolute value of the vorticity.

$F_{2}$ is given by

$$
F_{2}=\tanh \left(\arg _{2}^{2}\right),
$$

where $\arg _{2}=\max \left(2 \sqrt{k} / 0.09 \omega y, 500 \mu / \rho y^{2} \omega\right)$.

The constants $\phi$ of the SST model are calculated from the constants, $\phi_{1}, \phi_{2}$ as follows:

$$
\phi=F_{1} \phi_{1}+\left(1-F_{1}\right) \phi_{2},
$$

where set $1\left(\phi_{1}\right)$ is the constants of $k-\omega$ model and set $2\left(\phi_{2}\right)$ is the constants of $k-\varepsilon$ model.

The constants of set $1\left(\phi_{1}\right)$ are

$$
\begin{gathered}
\sigma_{k 1}=0.5, \quad \sigma_{\omega 1}=0.5, \quad \beta_{1}=0.075 \\
\beta^{*}=0.09, \quad \kappa=0.41, \quad \gamma_{1}=\left(\frac{\beta_{1}}{\beta^{*}}\right)-\left(\frac{\sigma_{\omega 1} \kappa^{2}}{\sqrt{\beta^{*}}}\right) .
\end{gathered}
$$

The constants of set $2\left(\phi_{2}\right)$ are

$$
\begin{gathered}
\sigma_{k 2}=1.0, \quad \sigma_{\omega 1}=0.856, \quad \beta_{2}=0.0828, \\
\beta^{*}=0.09, \quad \kappa=0.41, \quad \gamma_{2}=\left(\frac{\beta_{2}}{\beta^{*}}\right)-\left(\frac{\sigma_{\omega 2} \kappa^{2}}{\sqrt{\beta^{*}}}\right) .
\end{gathered}
$$

All other parameters are given in [14].
In this work, the far-field free stream condition is standard temperature and pressure $(101.325 \mathrm{kPa}, 288 \mathrm{~K})$ and the far-field boundary is based on Riemann invariants reflecting boundary conditions. The single reference frame (SRF) model is used to perform the problem of spinning rocket. The air is assumed as an ideal gas and the viscosity varies with temperature in accordance with Sutherland three coefficient formulas. The solution method is implicit formulation and Advection Upstream Splitting Method (AUSM). AUSM which is based on the finite volume method and is used to Spatial discrete the space of fluid field. Second Order Upwind scheme is used on convection and turbulent viscosity terms. Flow field mesh number is $800000, Y^{+}=30-100$ [15]. Flow field computation grid is shown in Figures 3(a) and 3(b).

Solving the above equations, density, velocity, pressure, and so forth could be computed at every grid node. Then, normal, axial, lift, drag, pitching moment, and center of the pressure coefficients can be obtained by following equations, respectively:

$$
\begin{aligned}
& C_{N}=\frac{N}{q_{\infty} S}, \\
& C_{A}=\frac{A}{q_{\infty} S},
\end{aligned}
$$

$$
C_{L}=C_{N} \times \cos \alpha-C_{A} \times \sin \alpha,
$$

$C_{D}=C_{N} \times \sin \alpha+C_{A} \times \cos \alpha$,

$$
\begin{gathered}
C_{m}=\frac{\text { pitching moment }}{q_{\infty} S l}, \\
x_{c p}=x_{c g}-\left(\frac{C_{m}}{C_{N}}\right),
\end{gathered}
$$

where $q_{\infty}, \alpha, S, x_{c p}$, and $x_{c g}$ are the dynamic pressure, angle of attack, reference area, center of pressure location, and center of gravity location, respectively. $l$ is length of the rocket. The vertex of the warhead is the reference point.

2.3.3. Static Structure Analysis Equations. A static structural analysis determines the displacements, stresses, strains, and forces in the structures or components caused by loads that do not induce significant inertia and damping effects. Steady loading and response conditions are assumed; that is, the loads and the structure's response are assumed to vary slowly with respect to time. This is an isotropic linear elastic problem. The static structure analysis equation can be written as

$$
[K]\{\delta\}=\{F\},
$$

where $[K]$ is stiffness matrix, $\delta$ is displacement vector, and $\{F\}$ is force vector.

To acquire the high quality mesh of the rocket, 10 nodes tetrahedron element (SOLID187) which is used for the wrap fins and warhead and 20 nodes hexahedron element (SOLID186) which is used for simple geometric part are used to perform the structural analysis. For these linear 


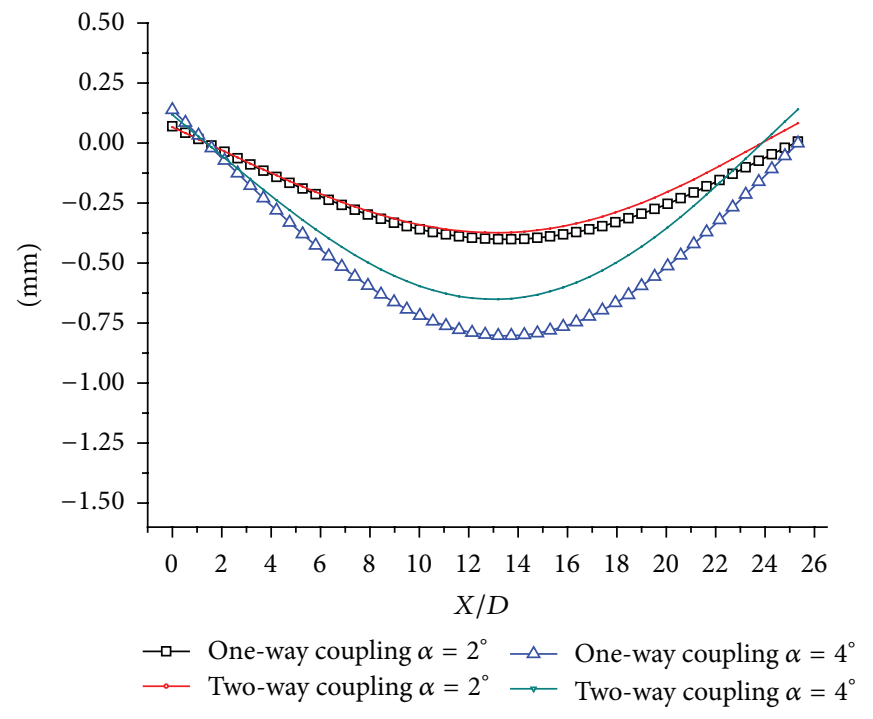

(a)

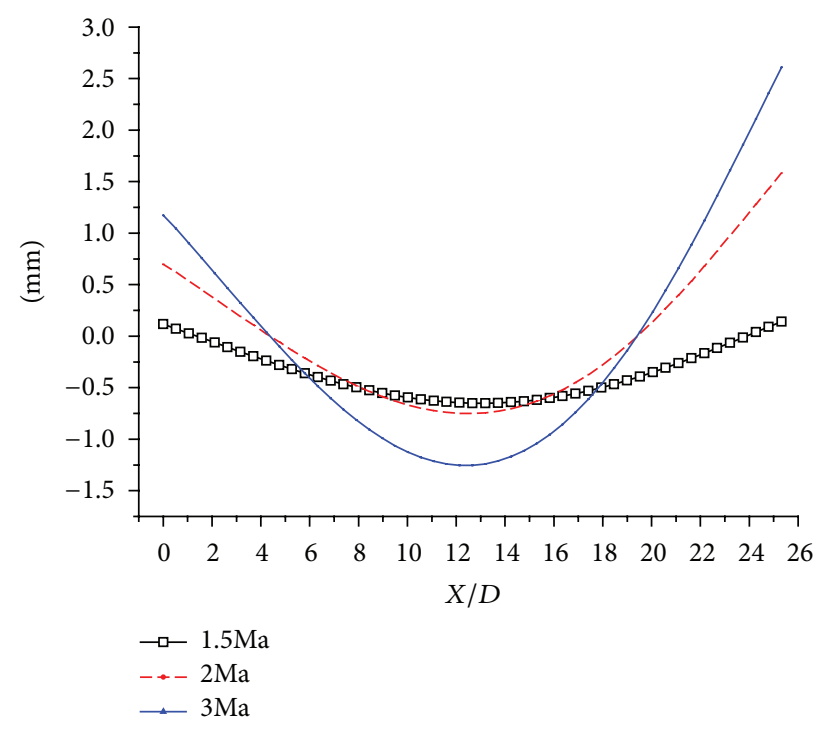

(b)

FIGURE 7: $Y$-direction deformation of nonspinning rocket body: (a) $Y$-direction deformation of nonspinning rocket body at Ma $=1.5$ and (b) $Y$-direction deformation of nonspinning rocket body at $\alpha=4^{\circ}$.

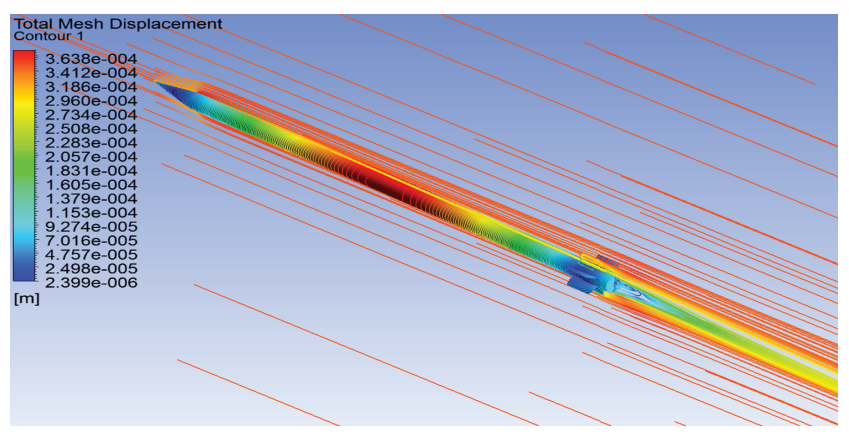

FIgURE 8: Total deformation and streamline contour at $\mathrm{Ma}=1.5$ and $\alpha=2^{\circ}$.

elastic structural mechanics problems, $K$ is a constant and aerodynamic force $F$ is calculated by CFD code. Then, the deformation $\delta$ can be obtained. The rocket solid region grid is shown in Figure 4.

Multipoint Constraint (MPC) approach is used to define the bonding of contact surfaces. Normal force and tangential force of each part are transferred through contact surfaces. Inertia relief method, which is based on d'Alembert principle and used to simulate unconstrained rockets in flight and make sure the rocket has no rigid body displacement, is used with the linear solver. In addition, because the body is rotating, a rotating angular velocity is applied to the rocket body.

Inertia relief is an approach in which the applied forces and torques are balanced by inertial forces induced by an acceleration field. Consider the application of an acceleration field (to be determined) that precisely balances the applied loads:

$$
\begin{aligned}
& \left\{F_{t}^{a}\right\}+\left[M_{t}\right]\left\{a_{t}^{1}\right\}=\{0\}, \\
& \left\{F_{r}^{a}\right\}+\left[M_{r}\right]\left\{a_{r}^{1}\right\}=\{0\},
\end{aligned}
$$

where

$\left\{F_{t}^{a}\right\}=$ force components of the applied load vector, $\left\{F_{r}^{a}\right\}=$ moment components of the applied load vector,

$\left\{a_{t}^{1}\right\}=$ translational acceleration vector due to inertia relief (to be determined),

$\left\{a_{r}^{1}\right\}=$ rotational acceleration vector due to inertia relief (to be determined),

$\{r\}=$ position vector $=[x, y, z]^{T}$,

$\left[M_{t}\right]=$ mass tensor for the entire finite element model (developed below),

$\left[M_{r}\right]=$ mass moments and mass products of the inertia tensor for the entire finite element model (developed below).

Once $\left[M_{t}\right]$ and $\left[M_{r}\right]$ are developed and $\left\{F_{t}^{a}\right\}$ and $\left\{F_{r}^{a}\right\}$ can be obtained from CFD output, then $\left\{a_{t}^{1}\right\}$ and $\left\{a_{r}^{1}\right\}$ in (21) can be solved. The output inertia relief summary includes $\left\{a_{t}^{1}\right\}$ (output as translational accelerations) and $\left\{a_{r}^{1}\right\}$ (output as rotational accelerations).

2.3.4. Coupling Boundary Conditions and Dynamic Mesh. In this fluid-structure interaction work, there is a boundary where the fluid and structural domains interactions occur at 


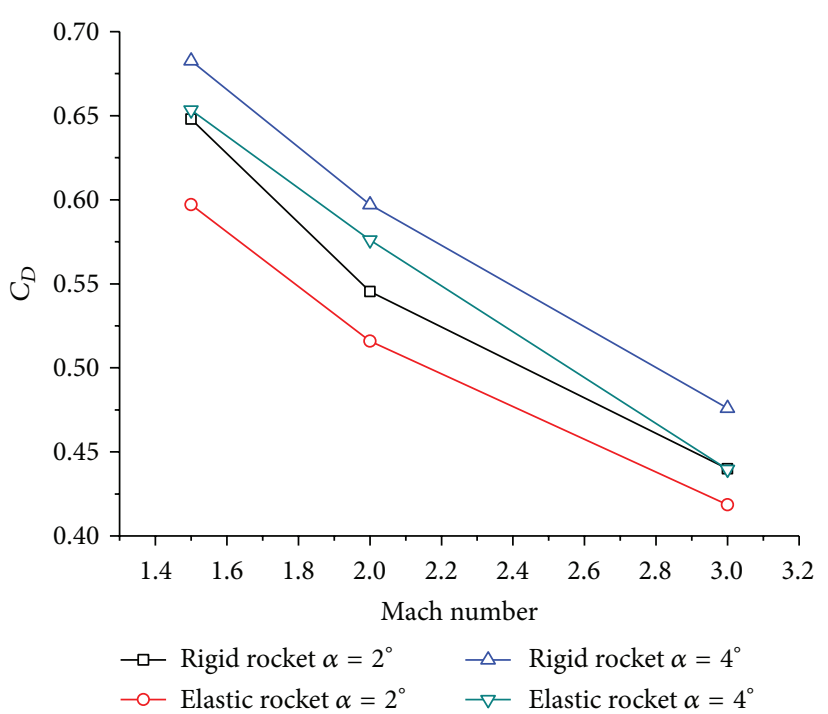

(a)

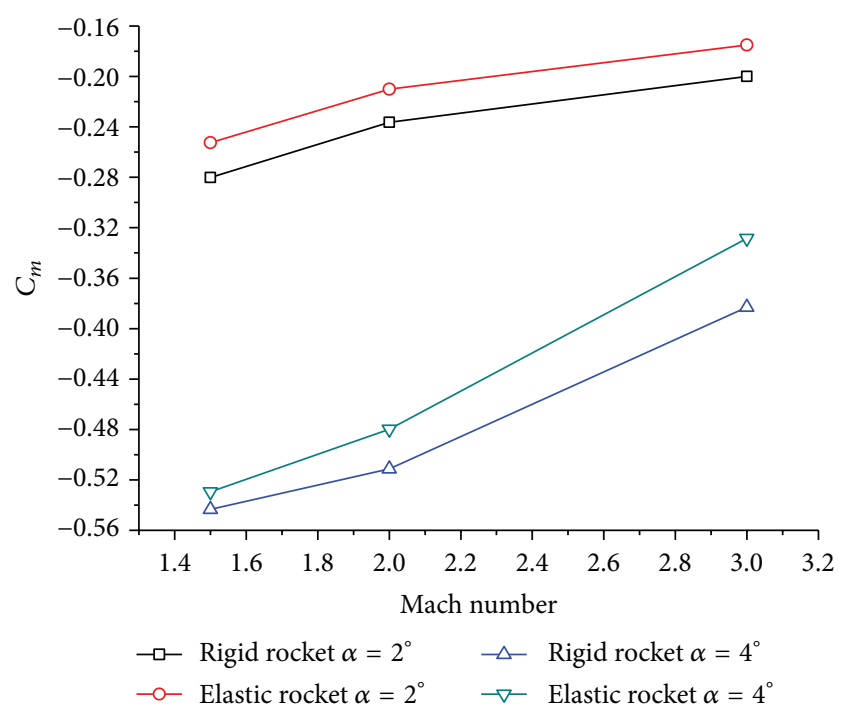

(c)

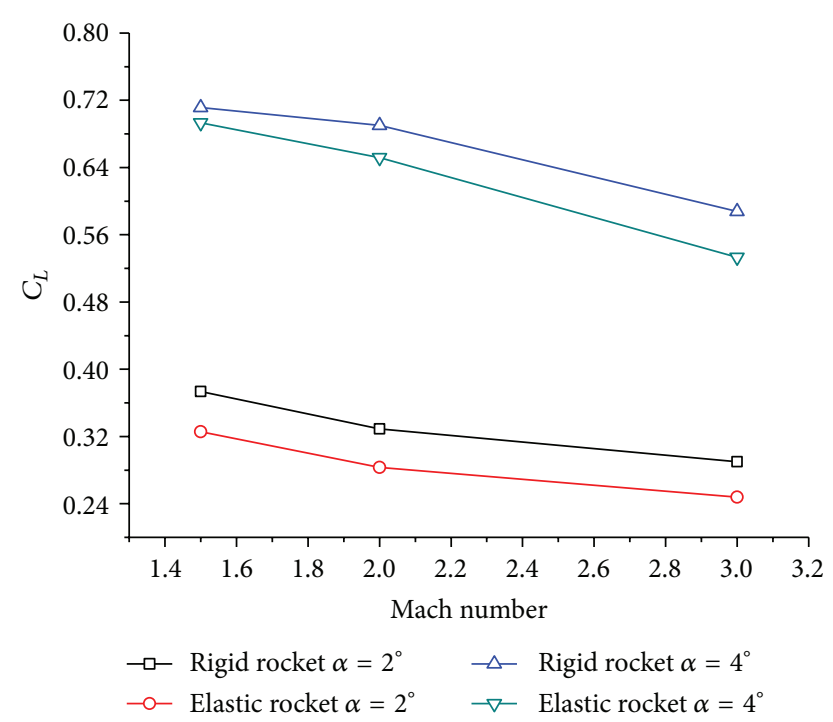

(b)

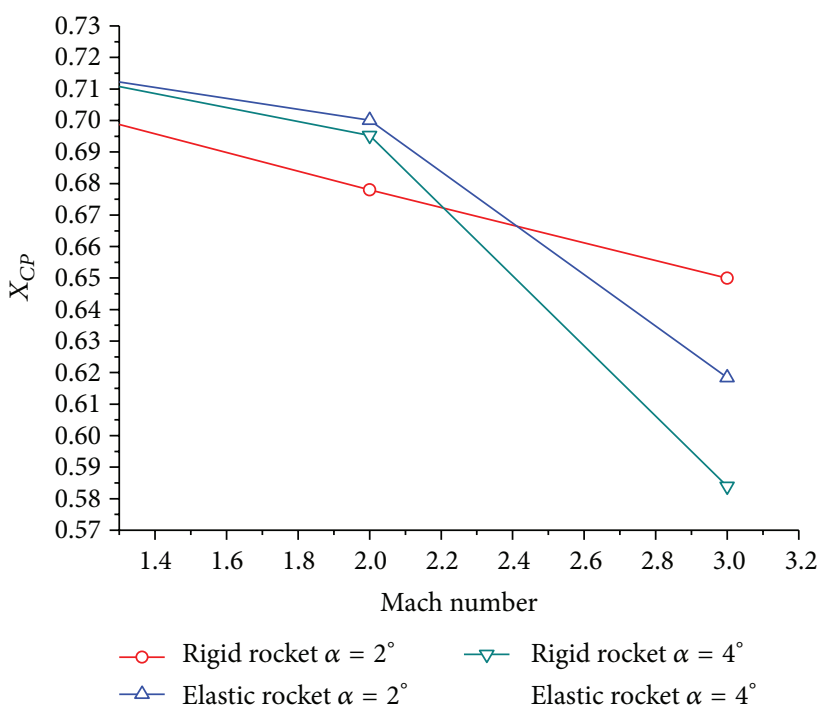

(d)

Figure 9: Aerodynamics coefficients versus Mach number (Ma) for elastic and rigid rocket: (a) $C_{D}$, (b) $C_{L}$, (c) $C_{m}$, and (d) $X_{c p}$.

this boundary or interface. Deformation compatibility conditions and force equilibrium conditions should be satisfied on the fluid-structure coupling interface as [16]

$$
\begin{aligned}
d_{f} & =d_{s}, \\
n \cdot \tau_{f} & =n \cdot \tau_{s}, \\
q_{f} & =q_{s}, \\
T_{f} & =T_{s},
\end{aligned}
$$

where $d, q, T$, and $\tau$ are displacement, heat flux, temperature, and stress field on the fluid-structure coupling interface, respectively. $n$ is the normal direction of interface. Subscripts $f$ and $s$ represent the fluid and the solid, respectively.

For data transfer of the dissimilar meshes, the interpolation operation is an essential step. The interpolation called globally conservative is used in this paper. It collects the interface meshes from the CFD code, does the mapping, and communicates stagger loop controls to the CFD code. The mapping generated by ANSYS code is used to interpolate loads between dissimilar meshes on either side of the coupling interface. Each field solver advances through a sequence of multifield stagger (coupling) iterations within each coupling step. During every stagger iteration, each field solver collects the loads that it requires from the other field solvers and then solves its physics fields. 
The flow field grids motion is achieved by diffusion-based smoothing method which is based on cell volume. And the mesh motion is governed by the diffusion equation:

$$
\nabla \cdot(\gamma \nabla \bar{u})=0
$$

where $\bar{u}$ is the mesh displacement velocity and $\gamma$ is the diffusion coefficient

$$
\gamma=\frac{1}{V^{\alpha}}
$$

where $V$ is the normalized cell volume and $\alpha$ is the user input parameter ( $\alpha=1.9$ in the present study). The boundary conditions for (23) are obtained from the computed boundary motion.

Equation (23) is discretized by finite volume method, and the resulting matrix is solved iteratively using the Algebraic Multigrid (AMG) solver. The cell centered solution for the displacement velocity $\bar{u}$ from (23) is interpolated onto the nodes using inverse distance weighted averaging, and the node positions are updated according to [17]:

$$
\bar{x}_{\text {new }}=\bar{x}_{\text {old }}+\bar{u} \Delta t
$$

For (25), $\Delta t$ is one coupling step that includes 1 3 iterations and one iteration includes 30 fluid solver iteration steps which make sure every coupling iteration step is converged. Use this method, decreasing the diffusivity in larger cells causes those cells to absorb more of mesh motion. It is better to preserve the cell quality of smaller cells which are close to the boundary motion and therefore preserve the computational accuracy.

\section{Presentation of Result}

Firstly, the aerodynamic coefficients of the rigid nonspinning rocket are calculated in the conditions of different Mach numbers, and the results are compared with the experimental data, which verified the accuracy of CFD output as shown in Figures 5(a), 5(b), and 5(c).

3.1. Static Aeroelastic Simulation Results of Nonspinning Rocket. Distributed normal force coefficients along rocket length at $\mathrm{Ma}=2,3$ and $\alpha=4^{\circ}$ of the rocket is shown in Figure 6. It reveals that the normal force of the warhead and tail of the rocket are larger than other parts of the rocket obviously. Then, these applied forces are balanced by inertial forces induced by an acceleration field according to inertial relief method and d'Alembert principle. Therefore, the rocket is bent upward (see Figures 7(a) and 7(b)).

One-way coupling is a method which is not considered as the influence of aerodynamic transformation due to elastic structure deformation. Firstly, the structural grid of the flow field around the required model is constructed to compute the aerodynamic pressures distribution along the whole rocket using CFD. Then, map the pressures at the CFD grid points to be replaced by forces on the CSD nodes. Consequently, stress and deformation distributions of the structure are obtained by CSD code. To obtain accurately

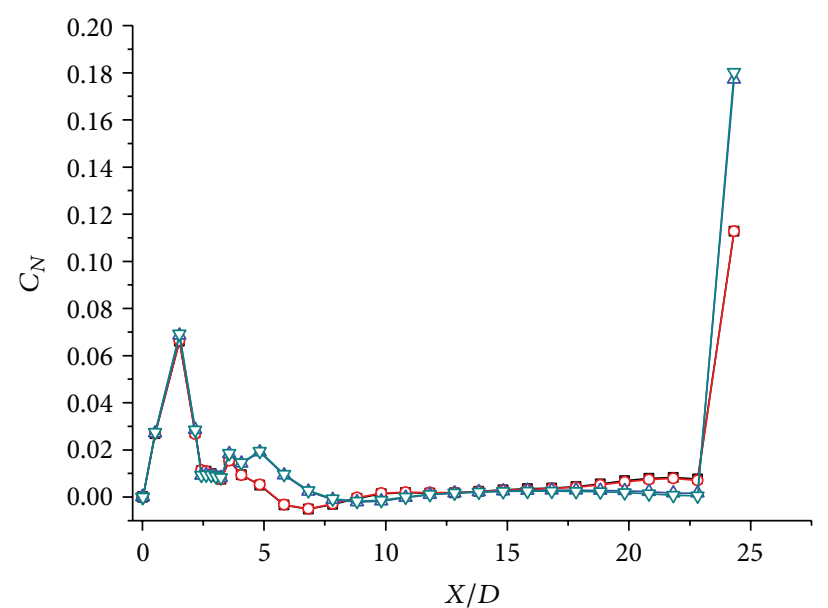

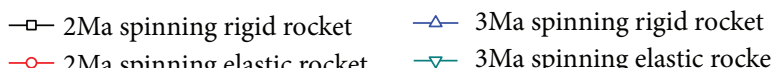

FIGURE 10: Spinning rocket distributed normal force coefficient along rocket length at $\mathrm{Ma}=2,3$ and $\alpha=4^{\circ}$.

the deformation and aerodynamic load distributions of the rocket, a two-way coupling method is applied and compared with one-way coupling method. The deformations of the nonspinning rocket, which are calculated by one-way and twoway couplings, are shown in Figure 7(a). These deformations are in the same magnitude with one-way coupling output, which is verified by the rationality of the two-way coupling output. The results show that the deformation levels of twoway coupling output are smaller in comparison with oneway coupling. It is due to the normal force of the deformed rocket becoming smaller than the rigid rocket. Obviously, with increasing the Mach number and angle of attack, the deformations of the rocket become larger as presented in Figures 7 (a) and 7(b). The total deformation and streamline contour of the rocket at $\mathrm{Ma}=1.5$ and $\alpha=2^{\circ}$ are shown in Figure 8 .

The changes of aerodynamic coefficients with Mach number of elastic rocket compared with the rigid ones are shown in Figures 9(a), 9(b), 9(c), and 9(d). It reveals that the drag and lift force coefficients decrease and pitching moment coefficients increase due to elastic deformations. Center of pressure coefficient moves forward (see Figure 9(d)), which contributes to the stability reduction of the rocket.

3.2. Static Aeroelastic Simulation Results of Spinning Rocket. Distributed normal force coefficient along rocket length at $\mathrm{Ma}=2,3$ and $\alpha=4^{\circ}$ of spinning elastic rocket is obtained and compared with a rigid one; result is shown in Figure 10. Obviously, the normal force in the warhead and tail of spinning rocket are higher than the cylinder part. For spinning rocket, the deformations in both $Y$ - and $Z$-directions are illustrated in Figures 11(a) and 11(b). Due to the lateral force generated by spinning, the deformation in $Z$-direction is slightly high. Therefore, spinning and two-way coupling method should be considered carefully in the design stages of the rocket. 


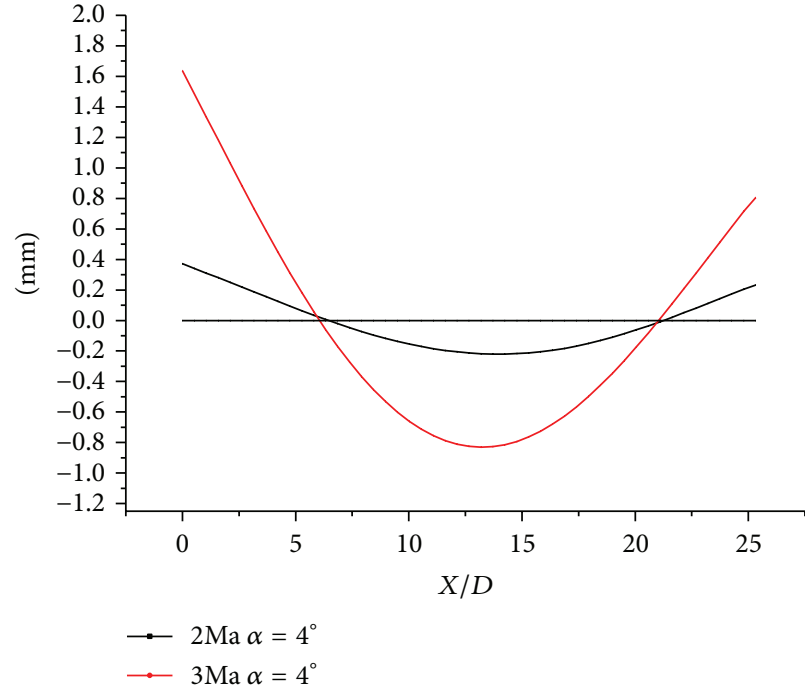

(a)

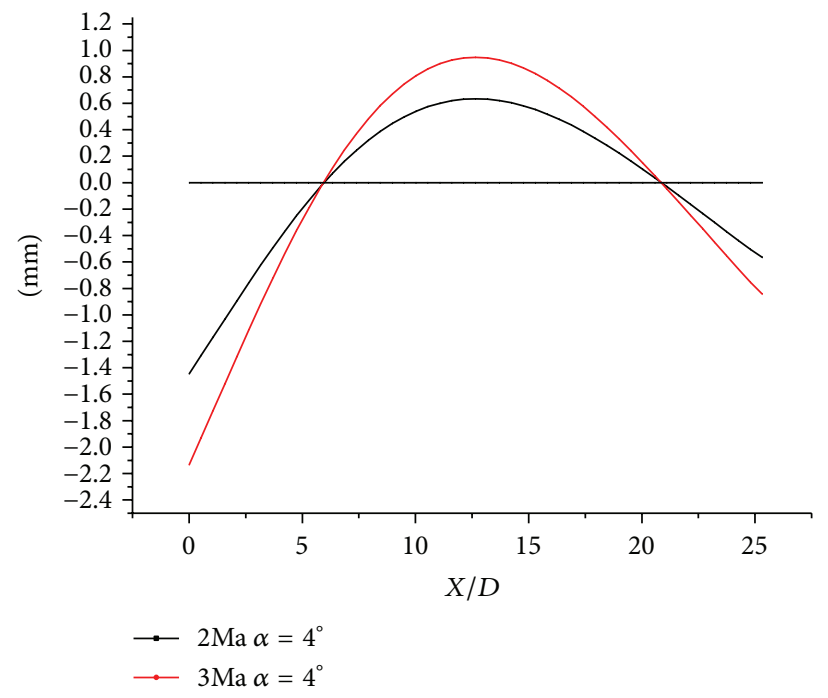

(b)

FIGURE 11: Deformations of spinning rocket body in: (a) $Y$-direction and (b) $Z$-direction.

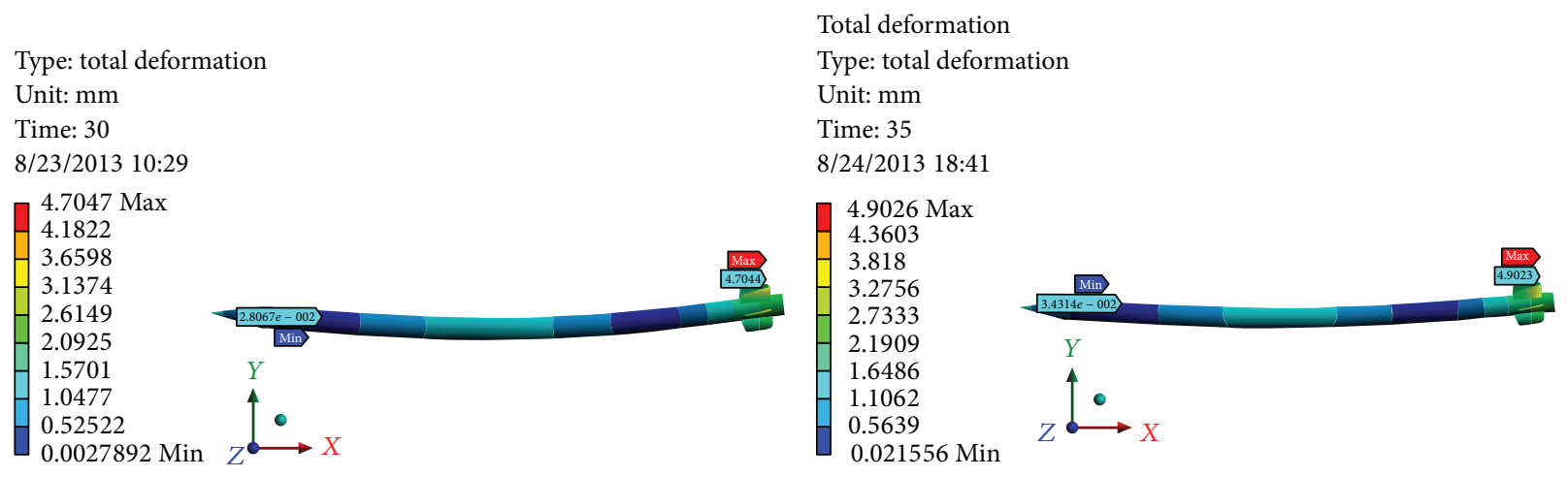

(a)

(b)

FIGURE 12: Total deformation distribution at $\mathrm{Ma}=3$ and $\alpha=4^{\circ}$ of the rocket: (a) nonspinning and (b) spinning.

Total deformation distribution of the nonspinning and spinning rockets is shown in Figures 12(a) and 12(b). The maximum deformation occurred in the wrap fins due to large aerodynamic loads. Elastic and rigid wrap fins pressure distributions of the intersecting line of spinning rocket are shown in Figure 13. The result shows that the deformation induced a significant effect on the aerodynamic characteristics of the wrap fin.

Comparison of the aerodynamic parameters for rigid and elastic rockets is given in Table 3. Results of drag, lift, pitching moment, and pressure center coefficients results for nonspinning and spinning elastic rocket compared with nonspinning and spinning rigid rocket and the result show that the aerodynamic coefficients are significantly affected by the static aeroelastic phenomenon via two-way coupling. The results show that lift and drag force coefficients are decreased by $1.8 \sim 7.6 \%$ and $0.06 \sim 9.3 \%$, respectively. Pitching moment coefficients are increased by $0.2 \sim 14.3 \%$ and the center of pressure location of elastic rocket moves forward by $0.4 \sim$ $5.8 \%$. In other words, the stability of the rocket is decreased by $0.4 \sim 5.8 \%$. That means elastic deformations contribute to the stability reduction of the rocket.

\section{Conclusions}

In this paper, in order to solve the static aeroelastic problem, a two-way coupling FSI method is introduced. ANSYS Workbench multiphysics coupling platform is used to determine the static aeroelastic behavior of the slender rocket. Diffusion-based smoothing method and inertia relief methods are used to calculate the static deformations and aerodynamic characteristics of the deformed rocket. With increasing the Mach number and angle of attack, the deformations of 
TABLE 3: Total rocket aerodynamic coefficients.

\begin{tabular}{|c|c|c|c|c|c|}
\hline Mach number & Rocket state & $C_{D}$ & $C_{L}$ & $C_{m}$ & $X_{\mathrm{cp}}$ \\
\hline \multirow{4}{*}{$2 \mathrm{Ma}$} & Nonspinning rigid rocket & 0.5967 & 0.6902 & -0.5112 & 0.700 \\
\hline & Nonspinning elastic rocket & 0.5764 & 0.6517 & -0.4799 & 0.695 \\
\hline & Spinning rigid rocket & 0.5673 & 0.3209 & -0.1654 & 0.459 \\
\hline & Spinning elastic rocket & 0.5567 & 0.3207 & -0.1650 & 0.457 \\
\hline \multirow{4}{*}{$3 \mathrm{Ma}$} & Nonspinning rigid rocket & 0.4759 & 0.5877 & -0.3831 & 0.618 \\
\hline & Nonspinning elastic rocket & 0.4396 & 0.5332 & -0.3285 & 0.582 \\
\hline & Spinning rigid rocket & 0.4608 & 0.4009 & -0.2101 & 0.486 \\
\hline & Spinning elastic rocket & 0.4467 & 0.4001 & -0.2096 & 0.484 \\
\hline
\end{tabular}

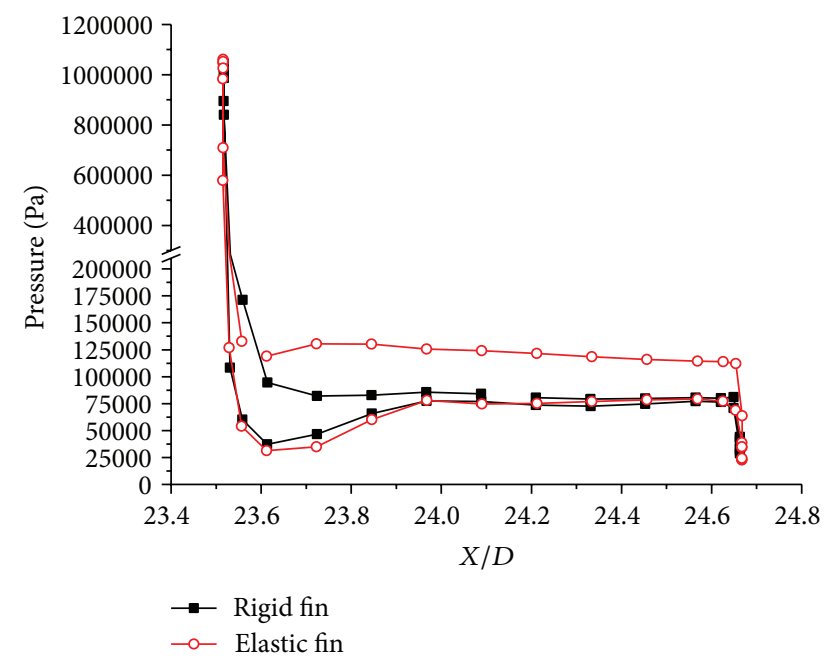

FIGURE 13: Pressure versus $x$-position on the intersecting line of $y=$ $0.3 \mathrm{~m}$ section of the wrap fin of spinning rocket at $\mathrm{Ma}=3$ and $\alpha=4^{\circ}$.

the rocket become large obviously. For spinning rocket, $Z$ direction is also deformed due to the lateral force generated by the spinning. The principle of the bending direction of the rocket is explained in this paper. The aerodynamic characteristics and stability of the rocket are changed significantly due to deformations. Consequently, spinning and two-way coupling should be considered carefully during the design.

\section{Conflict of Interests}

The authors declare that there is no conflict of interests regarding the publication of this paper.

\section{Acknowledgments}

This study was supported by Natural Science Foundation of China Government (no: 11102089) and Program for New Century Excellent Talents in University (NCET-10-0075).

\section{References}

[1] J. Sahu, H. L. Edge, K. R. Heavey, and E. N. Ferry, "Computational fluid dynamics modeling of multi-body missile aerodynamic interference," Tech. Rep. ARL-TR-1765, U.S. Army Research Laboratory, Aberdeen Proving Ground, Md, USA, 1998.

[2] J. DeSpirito and K. R. Heavey, "CFD computation of magnus moment and roll damping moment of a spinning projectile," in Proceedings of the AIAA Atmospheric Flight Mechanics Conference, pp. 139-154, August 2004.

[3] J. Despirito and P. Plostins, "CFD prediction of M910 projectile aerodynamics: unsteady wake effect on magnus moment," in Proceedings of the AIAA Atmospheric Flight Mechanics Conference, pp. 867-884, August 2007.

[4] B. P. Danowsky, P. M. Thompson, C. Farhat, T. Lieu, C. Harris, and J. Lechniak, "A complete aeroservoelastic model: incorporation of oscillation-reduction- control into a highorder CFD/FEM fighter aircraft model," in Proceedings of the AIAA Atmospheric Flight Mechanics Conference, August 2009.

[5] J. D. Baum, H. Luo, and E. L. Mestreau, "Recent developments of a coupled CFD/CSD methodology," in Computational Science, vol. 2073 of Lecture Notes in Computer Science, pp. 1087-1097, 2001.

[6] J. Gai and F. Liu, "Static aero-elastic computation with a coupled CFD and CSD method," Tech. Rep. AIAA-2000-0717, 2000.

[7] E. Başkut and A. Akgül, "Development of a coupling procedure for static aeroelastic analyses," Scientific Technical Review, vol. 61, no. 3-4, pp. 39-48, 2011.

[8] E. L. Blades and J. C. Newman, "Aeroelastic effects of spinning missiles," in Proceedings of the 48th AIAA/ASME/ASCE/ AHS/ASC Structures, Structural Dynamics, and Materials Conference, pp. 6599-6618, April 2007.

[9] D. Fan, Investigations of grid fins aerodynamic shape design and roll characteristics of wing-body configuration [Ph.D. thesis], Nanjing University of Science and Technology, Nanjing, China, 2011, (Chinese).

[10] Z. T. Chen and Q. Sun, "Applications of inertia relief method in aircraft static aero-elasticity," Flight Dynamics, vol. 26, no. 5, pp. 71-74, 2008 (Chinese).

[11] L. Liao, "A study of inertia relief analysis," Tech. Rep. AIAA 20112002, 2011.

[12] J. R. Wright and J. E. Cooper, Introduction to Aircraft Aeroelasticity and Loads, John Wiley \& Sons, 2007.

[13] F. R. Menter, "Zonal two equation k- $\omega$ turbulence models for aerodynamic flows," Tech. Rep. AIAA-93-2906, 1993.

[14] F. R. Menter, "Two-equation eddy-viscosity turbulence models for engineering applications," AIAA journal, vol. 32, no. 8, pp. 1598-1605, 1994.

[15] F. M. White, Viscous Fluid Flow, McGraw-Hill, New York, NY, USA, 2nd edition, 1991. 
[16] X. G. Song, L. Cai, and H. Zhang, ANSYS Fluid-Structure Coupling Analysis and Engineering Examples, Water Power Press, Beijing, China, 2012, (Chinese).

[17] FLUENT 14.5 User's Guide, 2013. 

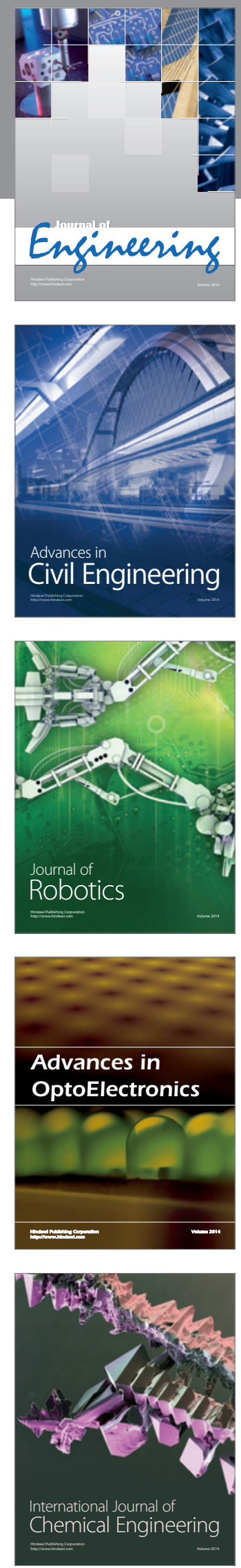

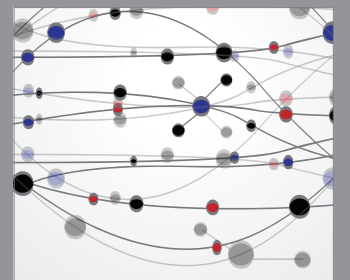

The Scientific World Journal
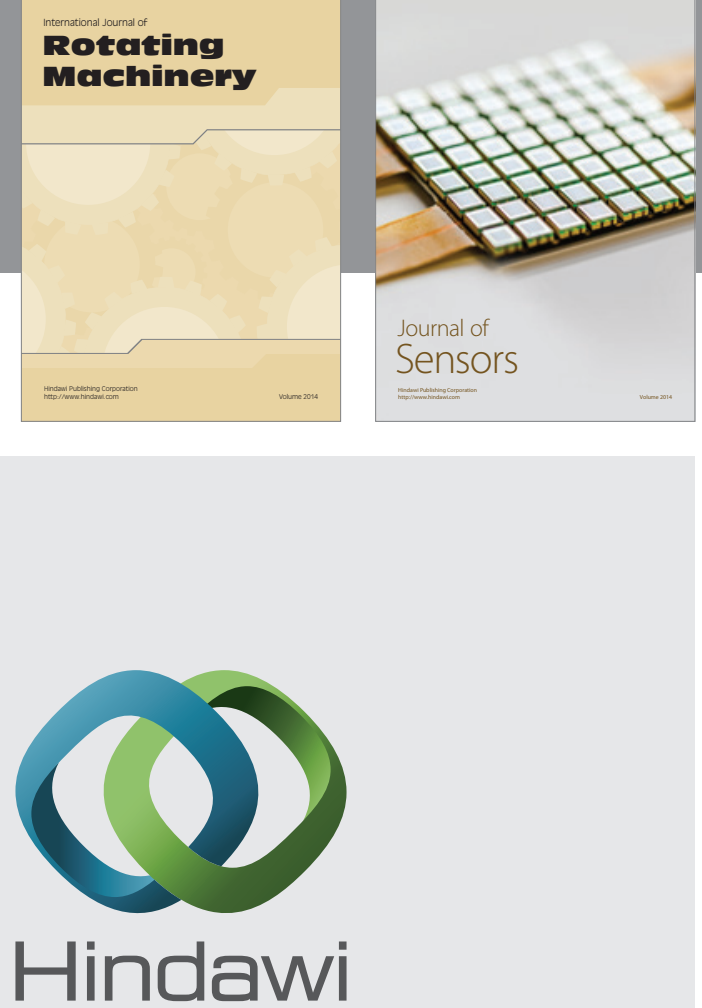

Submit your manuscripts at http://www.hindawi.com
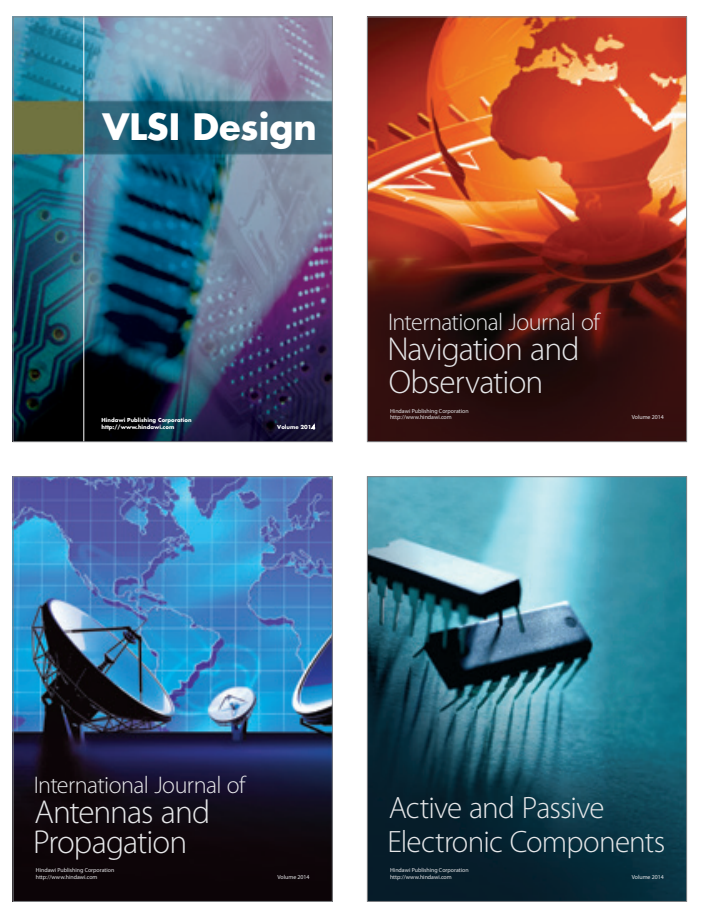
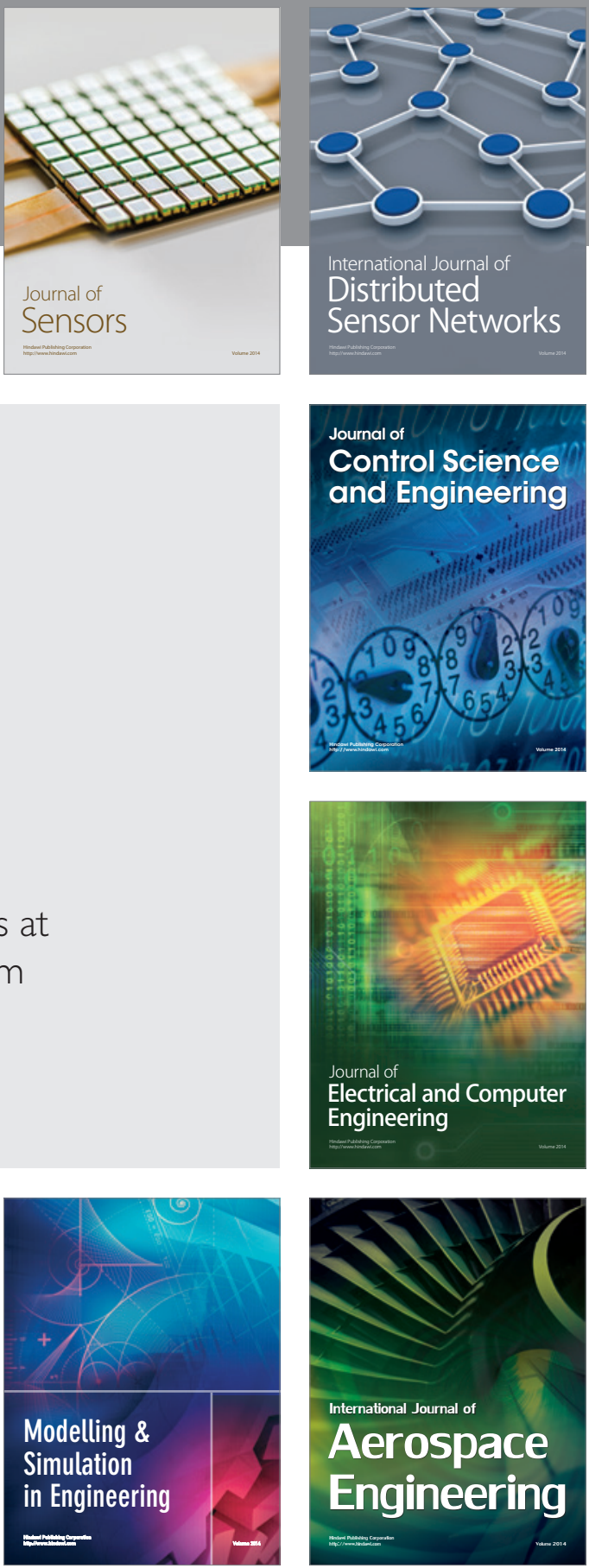

Journal of

Control Science

and Engineering
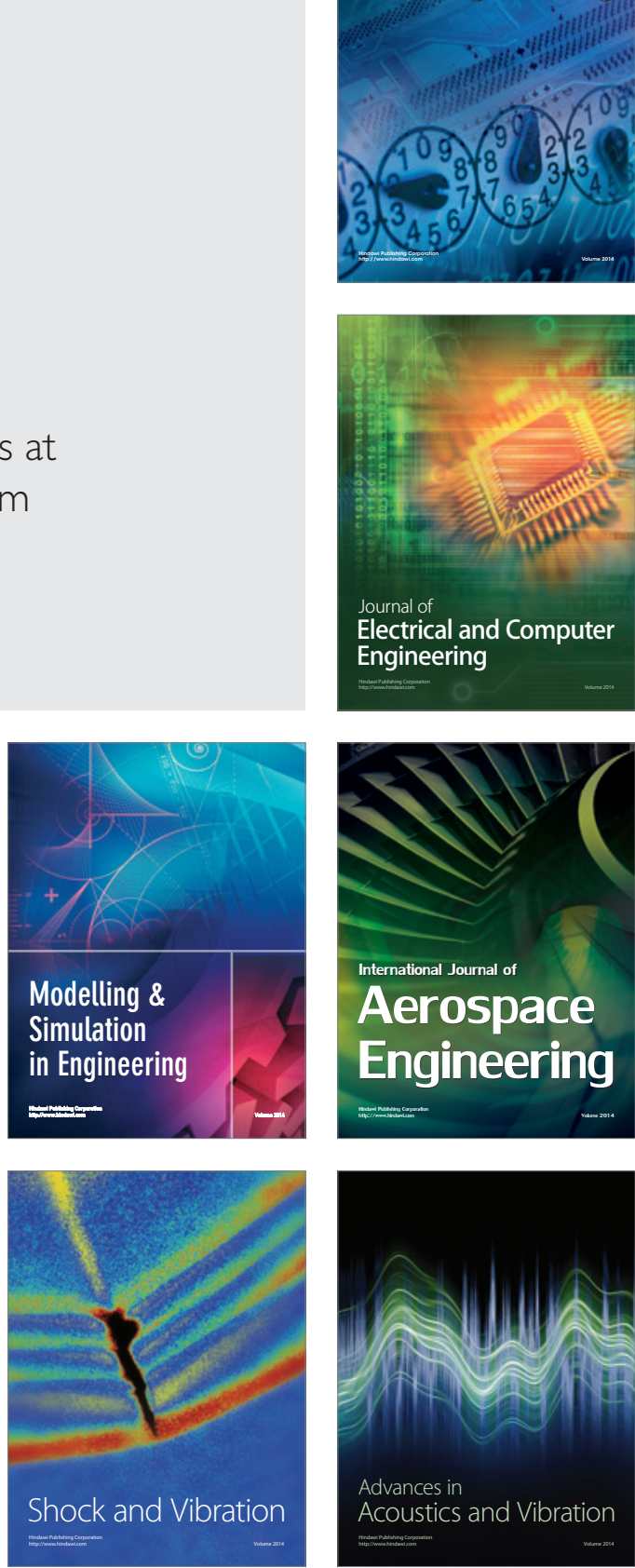